\title{
Retrospective analysis of primary and sequential care of type 2 diabetes patients in Taiwan
}

\author{
Ching-Hu Chung* \\ Department of Medicine, Mackay Medical College, New Taipei City, Taiwan
}

\begin{abstract}
Although oral antidiabetic drugs $(\mathrm{OADs})$ are the first choice for type 2 diabetes treatment, the progressive nature of the disease will require switching to another $\mathrm{OAD}$. The satisfaction of diabetes patients with current treatment is most unknown. We investigated the primary and sequential care of type 2 diabetes patients in Taiwan to understand the satisfaction of these diabetes patients. We used Taiwan's 2004-2008 National Health Insurance database to conduct a population-based, retrospective cohort study. The prevalence of diabetes in Taiwan increased from $3.95 \%$ to $4.45 \%$ from 2004 to 2008 . The one-year annual incidence density was $1.04 \%$ to $1.11 \%$ from 2005 to 2008 . The most frequent medication used in the primary care of type 2 diabetes patients was metformin (80.4\%). During the study period, 79.3\% of patients who used alpha glucosidase inhibitor modified their medication, and most of them switch to metformin as their second medication. Most patients who used metformin (76.8\%) as their initial OAD maintained their metformin treatment after 720 days. Our analysis suggests that there is a significantly higher adherence rate in new diabetes patients that receive metformin treatment. The low rates of discontinuation of metformin may also suggest that approximately $80 \%$ of the patients are adequately treated over longer periods.
\end{abstract}

\section{Introduction}

It is well known that the number of individuals with type 2 diabetes is increasing rapidly, and disease onset is occurring at progressively earlier ages [1]. The American Diabetes Association (ADA) estimates that that more than 25.8 million U.S. adults aged 20 years or older had diabetes in the year 2010 [2]. Diabetes is associated with comorbid disease states, so diabetes management has become ubiquitous in primary care [3]. This situation is a serious challenge, because the disease-related complications can tax the health-care system and increase the economic burden. Most patients begin treatment with diet and exercise changes or incorporate them into their treatment regimen. Although lifestyle intervention is the cornerstone of successful management for diabetes patients, the glycemic control in these patients is typically lost over time. As a result, most patients require continual treatment intensification with the use of oral antidiabetes agents (OADs) and often require insulin therapy.

It is important both to consider the individual's current situation when initiating pharmacotherapy, and to evaluate how they might achieve glycemic goals and additional benefits, such as improving other metabolic parameters or achieving long-term maintenance of glycemic control. A range of therapeutic classes of OADs, as well as insulin, which target different metabolic pathologies, are used to treat type 2 diabetes. Currently, there are five distinct classes of hypoglycemic agents available, with each class displaying unique pharmacologic properties. These classes are the sulfonylureas, biguanides, thiazolidinediones (TZD), alpha-glucosidase inhibitors and other blood glucose lowering drugs. Biguanides have been in use for many years, and metformin is the most important one in this antidiabetic class [4,5]. Metformin works by reducing hepatic glucose output and enhancing insulin sensitivity in hepatic and peripheral tissues. Metformin has been shown to reduce $\mathrm{HbA1C}$ by approximately $1.5 \%$, and FPG levels, as well $[4,6]$. Metformin also has been shown to decrease mortality and death from any cause independent of long-term glucose control [7]. Sulfonyurea monotherapy also effectively lowers HbA1C by approximately $1-2 \%$, and reduces fasting blood glucose $[8,9]$. Metformin and sulfonyureas have formed the backbone of OADs, and in more recent years, the TZDs have provided an increasingly significant component in UK [10]. Other classes of OADs have no major impact in most countries.

The American Diabetes Association and the European Association for the Study of Diabetes (ADA/EASD) have released a consensus algorithm for the initial management and the adjustment of therapy, as a guide to the treatment of type 2 diabetes [11-13]. The algorithm describes a stepped-care approach to treat the elevated levels of blood glucose and HbAlC. If medication is needed, this guideline recommends metformin as initial pharmacotherapy for type 2 diabetes, with an expected reduction in $\mathrm{HbA1C}$ of between $1.0 \%$ and $2.0 \%$ [12]. For patients unable to maintain their $\mathrm{HbAlC}$ goals, further choices include the addition of sulfonylurea, pioglitazone, GLP-1 agonist or the initiation of basal insulin to lifestyle changes and metformin. Although initial therapy is aimed at increasing the basal insulin supply, usually with intermediate or long-acting insulins, patients may also require prandial therapy with short or rapid-acting insulins [14].

Since the objective of the pharmacological treatment in T2DM is to control glycaemic parameters in order to minimize the risk of longterm complications, the better compliance for the initial treatment may associated with better outcome. In this study, our goal was to determine whether the real-world OAD prescription in Taiwan follows

Correspondence to: Ching-Hu Chung, Department of Medicine, Mackay Medical College, No. 46, Sec. 3, Zhongzheng Rd., Sanzhi Dist., New Taipei City, Taiwan, Tel: 886-2-26360303, Fax: 886-2-26361295, E-mail: chchung@mmc.edu.tw

Key words: diabetes, initial medication, metformin, taiwan

Received: February 03, 2017; Accepted: February 18, 2017; Published: February 21,2017 
the ADA/EASD algorithm and to understand OAD modification with different initial medications. We hypothesized that the sulfonylureas, TZD, alpha-glucosidase inhibitors and other blood glucose lowering drugs may be appropriate choices only in selected patients, and in most patients, these agents were not recommended as initial OADs. If Patients prescribed with these agents as their initial OAD, their medication will be modified quickly. To test this hypothesis, we used data from a medical claims database to estimate the OAD prescription every three months and then analyzed the sequential OAD usage in different treatment groups.

\section{Materials and methods}

\section{Data source and patient definition}

This was a retrospective cohort study using the claims records in the Longitudinal Health Insurance Database 2005 (LHID2005) for the years 2004-2008. LHID2005 contains all the original claims data of 1,000,000 beneficiaries, randomly sampled from the year 2005 Registry for Beneficiaries (ID) of the NHIRD. We used the International Classification of Diseases, Ninth Revision (ICD-9) Clinical Modification code to select patients with diabetes (ICD-9 codes 250); those who had not been diagnosed with diabetes during the year 2004 were defined as new diabetes patients in the ambulatory care (ambulatory care expenditures by visits) and inpatient care (inpatient expenditures by admissions) database from the year 2005 to 2008 . Those with a duration between first ICD-9 250 coding and an insulin prescription of less than 14 days were defined as type I diabetes and were excluded. The age and gender of the patients were also evaluated.

\section{Assessment}

The primary observation variable was the first $\mathrm{OAD}$ used by new type 2 diabetes patients. The medications used to treat diabetes were in accordance with the Anatomical Therapeutic Chemical (ATC) classifications [15]. OAD (A10B) usages were monitored in these patients. The OAD were categorized into five distinct classes, sulfonylureas, metformin, thiazolidinediones (TZD), alphaglucosidase inhibitors and other blood glucose lowering drugs. A consensus statement from the American Diabetes Association (ADA) and the European Association for the Study of Diabetes (EASD) recommends that metformin therapy (in the absence of contraindications) be initiated, concurrent with lifestyle intervention, at the time of diabetes diagnosis [12]. In patients with contraindications to metformin, the ADA/EASD consensus guideline suggests either insulin or a sulfonylurea [12]. We classified OAD used in five groups: (i) Metformin-based therapy (ii) sulfonylureas-based therapy (iii) TZD monotherapy (iv) alpha-glucosidase inhibitors monotherapy (v) other blood glucose lowering drugs monotherapy. We recorded the initial $\mathrm{OAD}$ used by the type 2 diabetes patients and their modification every six months.

\section{Data analyses}

SAS 9.1 (SAS Institute Inc., Cary, NC) was used for the data analyses. The variable measures were identified based on the criteria described above. The frequency/percentages were used to describe categorical variables, respectively.

\section{Results}

\section{Sample description}

In this original claims database of $1,000,000$ beneficiaries, the cumulative prevalence of diabetes in Taiwan had increased from $3.95 \%$ to $4.45 \%$ from 2004 to 2008 , and the one-year annual incidence density was $1.04 \%$ to $1.11 \%$ from 2005 to 2008 (Table 1). Data showed that $50.12 \%$ of diabetes patients were female and $49.88 \%$ were male. The mean age at first diagnosis of diabetes was 58.7 (female 59.5; male 57.8). Our results showed that the incidence was highest in the age group of $45-59$ years $(36.7 \%)$, and then $60-74$ years $(30.9 \%)$, and lowest in the age group of $0-14$ years $(0.4 \%)$.

\section{Patterns of drug prescribing}

Of these new diabetes patients $(\mathrm{n}=32,329), 17,750(54.9 \%)$ patients used OADs (Table 2). Among the OADs used to treat diabetes patients as the initial pharmacotherapy, metformin-based therapy $(\mathrm{n}=$ $14,254,80.4 \%$ ) was the most commonly prescribed, followed by alphaglucosidase inhibitors monotherapy $(\mathrm{n}=1,320,7.4 \%)$, sulfonylureasbased therapy $(n=1,012,5.7 \%)$ and TZD monotherapy $(n=660,3.7 \%)$ (Table 2).

\section{Medication change}

We checked the OAD medication every six months after the patients had received their initial OAD treatment. Only $14 \%$ of patients with initial Metformin-based therapy switch to alpha glucosidase inhibitors (1.6\%), sulfonylureas $(4.3 \%)$, TZD (6.6\%) or other glucose lowing agents (1.5\%) to their medication after six months of treatment (Table 3). After two years of treatment, $76.8 \%$ of patients still used the initial metformin-based therapy, and $23.2 \%$ of patients switch to alpha glucosidase inhibitors $(2.9 \%)$, sulfonylureas $(5.8 \%)$, TZD $(10.6 \%)$ or other glucose lowing agents (3.9\%). In the TZD monotherapy groups, about half $(59.8 \%)$ of the patients did not change their initial medication after two years of treatment. In the alpha glucosidase inhibitors and sulfonylureas-based therapy groups, less than $25 \%$ did not modify their initial medication after two years of treatment $(20.3 \%$ for alpha glucosidase inhibitors and $23.9 \%$ for sulfonylureas-based therapy).

\section{Discussion}

This study is one of few retrospective studies examining the initial therapy for diabetes patients by using a national sample in a non-

Table 1. Demographic distribution of the new diabetes patients.

\begin{tabular}{|c|c|c|c|c|c|}
\hline & 2004 & 2005 & 2006 & 2007 & 2008 \\
\hline Prevalence & $3.71 \%$ & $3.95 \%$ & $4.20 \%$ & $4.44 \%$ & $4.75 \%$ \\
\hline Incidence & & $1.04 \%$ & $1.05 \%$ & $1.06 \%$ & $1.11 \%$ \\
\hline $\begin{array}{c}\text { Patient number in } \\
\text { different age groups }\end{array}$ & $\begin{array}{c}\text { Female } \\
(\mathrm{n}=16,202,50.1 \%)\end{array}$ & $\begin{array}{c}\text { Male } \\
(\mathrm{n}=16,127, \\
49.9 \%)\end{array}$ & $\begin{array}{c}\text { Total } \\
(\mathrm{n}=32,329)\end{array}$ & & \\
\hline Age 0-14 & 61 & 77 & $138(0.4 \%)$ & \\
\hline Age 15-29 & 510. & 428 & $938(2.9 \%)$ & \\
\hline Age 30-44 & 1,916 & 2,284 & $4,200(13.0 \%)$ & \\
\hline Age 45-59 & 5,557 & 6,301 & $11,858(36.7 \%)$ & \\
\hline Age 60-74 & 5,450 & 4,539 & $9,989(30.9 \%)$ & \\
\hline Age more than 75 & 2,708 & 2,498 & $5,206(16.1 \%)$ & \\
\hline
\end{tabular}

Table 2. Initial medication of the diabetes patients.

\begin{tabular}{|c|c|c|c|}
\hline Patient number & Total & No OAD used & OAD used \\
\hline Metformin & 32,329 & 14,579 & 17,750 \\
\hline $\begin{array}{c}\text { Alpha glucosidase } \\
\text { inhibitor }\end{array}$ & & & $14,254(80.4 \%)$ \\
\hline $\begin{array}{c}\text { Sulfonamides urea } \\
\text { derivatives }\end{array}$ & & $1,320(7.4 \%)$ \\
\hline TZD & & $1,012(5.7 \%)$ \\
\hline $\begin{array}{c}\text { Other glucose lowing } \\
\text { agents }\end{array}$ & & $660(3.7 \%)$ \\
\hline
\end{tabular}


Table 3. The modification of OAD treatment in the new diabetes patients.

\begin{tabular}{|c|c|c|c|c|c|}
\hline Metformin & & & & & \\
\hline & $\begin{array}{l}\text { Alpha glucosidase } \\
\text { inhibitors }\end{array}$ & Metformin & Sulfonamides urea derivatives & Thiazolidinediones & Other \\
\hline 180 days & $1.60 \%$ & $86.00 \%$ & $4.30 \%$ & $6.60 \%$ & $1.50 \%$ \\
\hline 360 days & $1.90 \%$ & $82.80 \%$ & $4.50 \%$ & $8.00 \%$ & $2.70 \%$ \\
\hline 540 days & $2.60 \%$ & $79.80 \%$ & $5.50 \%$ & $8.90 \%$ & $3.30 \%$ \\
\hline 720 days & $2.90 \%$ & $76.80 \%$ & $5.80 \%$ & $10.60 \%$ & $3.90 \%$ \\
\hline \multicolumn{6}{|c|}{ Alpha glucosidase inhibitors } \\
\hline & $\begin{array}{l}\text { Alpha glucosidase } \\
\text { inhibitors }\end{array}$ & Metformin & Sulfonamides urea derivatives & Thiazolidinediones & Other \\
\hline 180 days & $33.20 \%$ & $44.30 \%$ & $5.90 \%$ & $14.40 \%$ & $2.20 \%$ \\
\hline 360 days & $28.70 \%$ & $46.50 \%$ & $7.20 \%$ & $14.50 \%$ & $3.10 \%$ \\
\hline 540 days & $21.00 \%$ & $44.80 \%$ & $8.30 \%$ & $21.00 \%$ & $4.40 \%$ \\
\hline 720 days & $20.30 \%$ & $43.40 \%$ & $10.40 \%$ & $22.50 \%$ & $3.30 \%$ \\
\hline \multicolumn{6}{|c|}{ Sulfonamides urea derivatives } \\
\hline & $\begin{array}{l}\text { Alpha glucosidase } \\
\text { inhibitors }\end{array}$ & Metformin & Sulfonamides urea derivatives & Thiazolidinediones & Other \\
\hline 180 days & $3.10 \%$ & $33.30 \%$ & $49.00 \%$ & $12.00 \%$ & $2.60 \%$ \\
\hline 360 days & $4.90 \%$ & $41.50 \%$ & $40.10 \%$ & $9.90 \%$ & $3.50 \%$ \\
\hline 540 days & $5.30 \%$ & $44.30 \%$ & $35.10 \%$ & $10.70 \%$ & $4.60 \%$ \\
\hline 720 days & $11.30 \%$ & $46.50 \%$ & $23.90 \%$ & $12.70 \%$ & $5.60 \%$ \\
\hline \multicolumn{6}{|c|}{ Thiazolidinediones } \\
\hline & $\begin{array}{l}\text { Alpha glucosidase } \\
\text { inhibitors }\end{array}$ & Metformin & Sulfonamides urea derivatives & Thiazolidinediones & Other \\
\hline 180 days & $1.50 \%$ & $10.80 \%$ & $3.90 \%$ & $81.40 \%$ & $2.50 \%$ \\
\hline 360 days & $1.30 \%$ & $22.80 \%$ & $4.00 \%$ & $69.10 \%$ & $2.70 \%$ \\
\hline 540 days & $7.50 \%$ & $21.80 \%$ & $2.70 \%$ & $60.50 \%$ & $7.50 \%$ \\
\hline 720 days & $3.30 \%$ & $27.20 \%$ & $4.30 \%$ & $59.80 \%$ & $5.40 \%$ \\
\hline
\end{tabular}

Western country. Using a large nationwide health insurance database, we found that OAD prescription in Taiwan follows the ADA/EASD algorithm, and most new diabetes patients receive metformin-based therapy as their initial OAD (80.4\%). Besides blood glucose lowering and HbAlc control, another goal of the ADA/EASD algorithm was to enhance adherence. After a successful initial response to oral therapy, patients failed to maintain target A1C levels $(<7 \%)$ at a rate of $5-10 \%$ per year $[16,17]$. Our analysis suggests a significantly higher adherence rate for new diabetes patients receiving metformin-based therapy (after two years of treatment, metformin $76.8 \%$ vs TZD 59.8\%, alpha glucosidase inhibitors $20.3 \%$ and sulfonylureas-based therapy $23.9 \%$ ). The low discontinuation rates of metformin-based therapy may also suggest that approximately $80 \%$ of the patients are adequately treated over longer periods. Our analysis was consistent with that of recent studies [18-20]. These findings provide additional valuable information to clinicians, patients and the public regarding the adoption and safety of metformin as an initial medication for new diabetes patients.

In this study, almost half of the patients used TZD as their second medication when initial metformin therapy failed. Einhorn et al. found that the introduction of pioglitazone to patients with type 2 diabetes poorly controlled on metformin alone achieved a greater reduction of HbA1c and fasting plasma glucose levels [21]. TZD may be the most appropriate option for patients when hypoglycemia is to be avoided; this was also suggested by Nathan, et al. [22, 23] The efficacy of TZDs in improving glycemic control, as measured by a reduction in $\mathrm{HbA1c}$ and fasting plasma glucose levels, has been well established in several placebo control studies [24,25]. Although patients receiving rosiglitazone therapy were at higher risk for cardiovascular events than those receiving metformin therapy, $3.7 \%$ of new diabetes patients still received TZD as their initial OAD in our study, similar to the results of other studies $[12,20]$. Patients who received TZDs as their initial OAD also had higher adherence rates than those receiving alpha glucosidase inhibitors and sulfonylureas-based therapy (Table 3). In patients with contraindications to metformin, the 2009 ADA/EASD recommended against the use of pioglitazone, rather than rosiglitazone, owing to concerns regarding safety and the availability of alternative therapies [22]. Pioglitazone may be considered in patients who have specific contraindications to sulfonylureas or those with lower initial A1C values.

There are several limitations to claims-based analyses, such as the incomplete nature of the data and the possibility of coding errors or coding omissions. First, the present study, based on a claims dataset, lacked detailed patient medical record information to validate the data, and lacked clinical information on HbAlc results that would allow us to assess disease control. Another limitation is the time lag in obtaining the NHIRD, since NHRI needs nearly one year to update the claims database. At the time we applied for the BNHI database, only data for years 1996 to 2008 were available, so year 2008 was the last year we could use to analyze the initial OAD used in new diabetes patients, and we were unable to observe the impact of the ADA/EASD guidelines published in 2009. GLP-1 receptor agonists and Sodium glucose cotransporter 2 (SGLT-2) inhibitors are two types of new T2D Pharmacotherapy [13]. Although they are used for diabetes treatment for several years around the world, we are unable the check their usage due to the BNHI database which we applied is year 2004-2008. Even in year 2009, the DPP4-inhibitors prescription used as monotherapy is only about $0.52 \%$ [5]. We will use the most update data to study these new $\mathrm{OAD}$ in further study.

Results from this study suggest that physicians generally adhere to T2D ADA/EASD guidelines for initial OAD medication. Since the OAD modification pattern was low in patients with initial metforminbased therapy, these results suggest that approximately $80 \%$ of patients are adequately treated with metformin-based therapy during two years of treatment. Many patients change in initial OAD therapy is observed 
in the first year of therapy, particularly with initial Alpha glucosidase inhibitors and Sulfonamides urea derivatives monotherapy. This suggests that their initial therapy was often unsatisfactory. New users of OADs may benefit from effectiveness of proportions of patients on initial therapy, especially metformin-based therapy.

\section{Competing interest}

Nothing to declare.

\section{Acknowledgements}

This study is based, in part, on data from the National Health Insurance Research Database (NHIRD) provided by the BNHI, Department of Health and managed by the National Health Research Institutes (NHRI). The interpretation and conclusions contained herein do not represent those of the NHRI or BNHI, Department of Health. This work was supported by Mackay Medical College [grant number MMC-1031A02, 1042E01, 1051C01, 1051E02 and 1051B08].

\section{Declaration of competing interests}

None to declare.

\section{References}

1. Jiang YD, Chang CH, Tai TY, Chen JF, Chuang LM (2012) Incidence and prevalence rates of diabetes mellitus in Taiwan: analysis of the 2000-2009 nationwide health insurance database. J Formos Med Assoc 111: 599-604. [Crossref]

2. National Institutes of Health. National diabetes statistics. Available at: diabetes.niddk. nih.gov/dm/pubs/statistics/index.htm[Accessed 23 March 2011].

3. Unger J (2007) Diagnosis and management of type 2 diabetes and prediabetes. Prim Care 34: 731-759. [Crossref]

4. DeFronzo RA, Goodman AM (1995) Efficacy of metformin in patients with noninsulin-dependent diabetes mellitus. The multicenter metformin study group. $N$ Engl JMed 333: 541-549. [Crossref]

5. Chang CH, Jiang YD, Chung CH, Ho LT, Chuang LM (2012) National trends in antidiabetic treatment in Taiwan, 2000-2009. J Formos Med Assoc 111(11): 617-624. [Crossref]

6. DeFronzo RA (1999) Pharmacologic therapy for type 2 diabetes mellitus. Ann Intern Med 131: 281-303. [Crossref]

7. Holman RR, Paul SK, Bethel MA, Matthews DR, Neil HA (2008) 10-year follow-up of intensive glucose control in type 2 diabetes. $N$ Engl J Med 359: 1577-1589. [Crossref]

8. (1998) United Kingdom prospective diabetes study 24: a 6-year, randomized, controlled trial comparing sulfonylurea, insulin, and metformin therapy in patients with newly diagnosed type 2 diabetes that could not be controlled with diet therapy. United Kingdom prospective diabetes study group. Ann Intern Med 128: 165-175. [Crossref]

9. Testa MA, Simonson DC (1998) Health economic benefits and quality of life during improved glycemic control in patients with type 2 diabetes mellitus: a randomized, controlled, doubleblind trial. JAMA 280: 1490-1496. [Crossref]

10. NICE, NICE implementation uptake report : glitazones (rosiglitazone and pioglitazone). Available at: http://www.nice.org.uk/using guidance/evaluation and review of nice implementation evidence ernie/nice implementat on uptake commission edreports/p279.jsp[Accessed 9 March 2011].
11. Nathan DM, Buse JB, Davidson MB, Heine RJ, Holman RR, et al. (2006) Management of hyperglycaemia in type 2 diabetes: a consensus algorithm for the initiation and adjustment of therapy. A consensus statement from the American Diabetes Association and the European Association for the Study of Diabetes. Diabetologia 49: 1711-1721. [Crossref]

12. Nathan DM, Buse JB, Davidson MB, Ferrannini E, Holman RR, et al (2009) Medical management of hyperglycemia in type 2 diabetes: a consensus algorithm for the initiation and adjustment of therapy: a consensus statement of the American Diabetes Association and the European Association for the Study of Diabetes. Diabetes Care 32: 193-203. [Crossref]

13. Garber AJ, Abrahamson MJ, Barzilay JI, Blonde L, Bloomgarden ZT, et al. (2016) Consensus statement by the american association of clinical endocrinologists and american college of endocrinology on the comprehensive type 2 diabetes management algorithm - 2016 executive summary. Endocr Pract 22: 84-113. [Crossref]

14. LeRoith D, Levetan CS, Hirsch IB, Riddle MC (2004) Type 2 diabetes: the role of basal insulin therapy. J Fam Pract 53: 215-222.

15. Skrbo A, Begović B, Skrbo S (2004) Classification of drugs using the ATC system (anatomic, therapeutic, chemical classification) and the latest changes. Med Arh 58: $138-141$

16. (1998) Intensive blood-glucose control with sulphonylureas or insulin compared with conventional treatment and risk of complications in patients with type 2 diabetes (UKPDS 33). UK Prospective Diabetes Study (UKPDS) Group. Lancet 352(9131): 837-853. [Crossref]

17. (1995) UK prospective diabetes study 16. Overview of 6 years' therapy of type II diabetes: a progressive disease. U.K. Prospective diabetes study group. Diabetes 44 1249-1258. [Crossref]

18. Huang EA, Zdon GS, Moore RJ, Jane Moran H, Quick WW (2010) Quick, The impact of publishing medical specialty society guidelines on subsequent adoption of best practices: a case study with type 2 diabetes. Int J Clin Pract 64: 558-561. [Crossref]

19. Lamberts EJ, Nijpels G, Welschen LM, Hugtenburg JG, Dekker JM, et al. (2011) Long term patterns of use after initiation of oral antidiabetic drug therapy, Pharmacoepidemiol Drug Saf 20: 351-358. [Crossref]

20. Grégoire JP, Sirois C, Blanc G, Poirier P, Moisan J (2010) Persistence patterns with oral antidiabetes drug treatment in newly treated patients--a population-based study. Value Health 13: 820-828. [Crossref]

21. Einhorn D, Rendell M, Rosenzweig J, Egan JW, Mathisen AL, et al. (2000) Pioglitazone hydrochloride in combination with metformin in the treatment of type 2 diabetes mellitus: a randomized, placebo-controlled study. The Pioglitazone 027 Study Group. Clin Ther 22: 1395-1409. [Crossref]

22. Nathan DM, Buse JB, Davidson MB, Ferrannini E, Holman RR, et al. (2009) Zinman, Medical management of hyperglycaemia in type 2 diabetes mellitus: a consensus algorithm for the initiation and adjustment of therapy: a consensus statement from the American Diabetes Association and the European Association for the Study of Diabetes. Diabetologia 52: 17-30.

23. Seufert J (2009) The backbone of oral glucose-lowering therapy: time for a paradigm shift? Fundam Clin Pharmacol 23: 651-667. [Crossref]

24. Aronoff S, Rosenblatt S, Braithwaite S, Egan JW, Mathisen AL, et al. (2000) Pioglitazone hydrochloride monotherapy improves glycemic control in the treatment of patients with type 2 diabetes: a 6-month randomized placebo-controlled dose-response study. The Pioglitazone 001 Study Group. Diabetes Care 23: 1605-1611. [Crossref]

25. Lebovitz HE, Dole JF, Patwardhan R, Rappaport EB, Freed MI, et al. (2001) Rosiglitazone monotherapy is effective in patients with type 2 diabetes. $J$ Clin Endocrinol Metab 86: 280-288. [Crossref]

Copyright: (C2017 Chung C. This is an open-access article distributed under the terms of the Creative Commons Attribution License, which permits unrestricted use, distribution, and reproduction in any medium, provided the original author and source are credited. 